\title{
Phenotypic Characteristics of a Slow-growing, Nongerminating Variant of Candida albicans
}

\author{
By DEXTER H. HOWARD, ${ }^{*}$ MARIE L. ZEUTHEN AND NINA DABROWA \\ Department of Microbiology and Immunology, UCLA School of Medicine, Los Angeles, \\ California 90024, USA
}

(Received 9 December 1985)

\begin{abstract}
Some of the phenotypic characteristics of a slow-growing, nongerminating variant of a commonly studied strain of Candida albicans are described. The variant arose as a chance isolate. The rate of occurrence was about $0.1 \%$ and the reversion rate was about 1 per $10^{6}$ cells. The colony size was typically smaller than that of the parent and the yeast cells tended not to separate from one another so that catenulate strands of cells (pseudohyphae) were formed. Under standard conditions the generation time of the small-colony variant in liquid shake cultures was about twice that of the parental strain. Growth of the variant was suppressed by antimycin A, indicating that the small colony form was not the consequence of a defect in the cytochrome system. The colony size of the variant was not influenced by chlorobenzotriazole, which suggested that adenine metabolism was not involved in the small-colony phenotype. The pseudohyphal growth pattern was not relieved by high concentrations of utilizable carbohydrates, which means the catenulate microscopic appearance of the yeast cells was not simply an exaggeration of the normal growth pattern of isolates of $C$. albicans but more probably represented the growth of a cell-cycle mutant defective at the cell separation step. The cytoplasmic proteins of the variant and the parent were very similar though some unique peptides were displayed by each.
\end{abstract}

\section{INTRODUCTION}

Candida albicans is a polymorphic, opportunistic, zoopathogenic fungus which grows as a budding yeast (blastoconidia), as a pseudohypha of elongated yeast cells, and as a true, septate hypha (Meyer et al., 1984; Odds, 1979). The true hyphal form of growth is initiated by germination of the blastoconidia (Dabrowa \& Howard, 1983; Szaniszlo et al., 1983), and interest in this germination event centres in the developmental biology of the fungus and in the possible role of germ tube formation in the pathogenesis of candidiasis (Ahrens et al., 1983; Brown \& Chaffin, 1981; Brummel \& Soll, 1982; Cassone et al., 1985; Martin et al., 1984; Manning \& Mitchell, 1980; Odds, 1979; Sobel et al., 1984; Szaniszlo et al., 1983).

The search for a differential expression of the genome of $C$. albicans in germination would be facilitated by a comparative study with nongerminating variants (Dahlberg \& Van Etten, 1982). Although germ-tube-negative isolates are encountered in the clinical laboratory (Beneke \& Rogers, 1980; McGinnis, 1980; Ogletree et al., 1978; Dolan \& Ihrke, 1971), the occurrence is often related to the method employed in the test, especially the inoculum size (D. H. Howard, unpublished observations; Martin et al., 1984; Ogletree et al., 1978). Stable nongerminating isolates whose inability to germinate is not related to the methods employed in the germ tube test are fairly uncommon but have been consistently recorded in the literature (see for example Mardon et al., 1969; Ogletree et al., 1978; Torosantucci \& Cassone, 1983; Martin et al., 1984). However, such encountered strains are usually single isolates and the germination-competent parent is accordingly unavailable for comparison. 
There have been few efforts to induce nongerminating mutants with mutagenic agents such as UV irradiation (D. Oblack, unpublished observations; Pomes et al., 1985) or nitrosoguanidine (D. H. Howard, unpublished observations). However, naturally occurring nongerminating variants of stock cultures have been recorded. For example, Buckley et al. (1982) reported the isolation of such a variant from strain $3153 \mathrm{~A}$ of $C$. albicans. This isolate was one of five such variants from strain 3153A discovered by Buckley and used by Olaiya et al. (1980) in their work on a haploid state in C. albicans. The strain 3153A (MRL 3153 of the Mycology Reference Laboratory, London, UK) is the same as the B311 strain of H. F. Hasenclever (see, e.g., Hasenclever, 1965) and is deposited in the American Type Culture Collection as ATCC 32354. Buckley et al. (1982) reported that the nongerminating variant (labelled B311-V6) occurred at a frequency of $2 \%$. This exceptionally high frequency suggested that strain $3153 \mathrm{~A}$ might provide nongerminating variants regularly and we investigated this possibility. We did not discover nongerminating variants at the same frequency as did Buckley et al. (1982), but we did isolate a small-colony form which did not germinate in any of the customary media designed to reveal germ tube formation (Dabrowa \& Howard, 1983). The colonial size of the variant was a reflection of its slow growth rate; a preliminary characterization of the strain, labelled 3153ASG, has been published (Dabrowa \& Howard, 1984). We now provide a more complete description of its phenotypic characters and compare these characters with those of other smallcolony forms of $C$. albicans recorded in the literature.

The strain 3153A which is the same as B311 (see above) has given rise to another nongerminating variant (PCA-2) in another laboratory (A. Cassone, personal communication). Thus nongerminative variants occur, at least in some strains, with a frequency that makes their isolation relatively easy. Our cumulative experience with the phenotypic characteristics of a number of such variants of $3153 \mathrm{~A}$ as well as those from other stock cultures will be the subject of another publication.

\section{METHODS}

Organisms. Candida albicans strains 300 and 300-SG were used in this study. Strain 300 is ATCC 32354 and has also been identified with the following numbers in various studies: 3153A (Dabrowa \& Howard, 1984), B311 (Hasenclever, 1965), and B311-10 (Buckley et al., 1982). Strain 300-SG has been used in a previous study under the number of 3153A-SG (Dabrowa \& Howard, 1984). Stock cultures are preserved in the Fungus Collection, University of California, Los Angeles, Calif., USA. Working cultures were maintained on glucose peptone agar in a refrigerator and were subcultured every month.

Media. Glucose peptone agar (GPA) contained 2\% (w/v) Bacto Dextrose (Difco), $1 \%$ (w/v) Bacto Peptone (Difco), and 2\% (w/v) Bacto Agar (Difco). Glucose peptone broth (GPB) had the same constituents without the agar. Yeast Nitrogen Base without amino acids (YNB) was prepared in accordance with the manufacturer's instructions (Difco). LBC synthetic medium (Lee et al., 1975) consisted of: $\left(\mathrm{NH}_{4}\right)_{2} \mathrm{SO}_{4}, 5 \mathrm{~g} ; \mathrm{MgSO}_{4} \cdot 7 \mathrm{H}_{2} \mathrm{O}, 0 \cdot 2 \mathrm{~g}$; $\mathrm{K}_{2} \mathrm{HPO}_{4}, 2.5 \mathrm{~g} ; \mathrm{NaCl}, 5 \mathrm{~g}$; glucose, $12.5 \mathrm{~g}$; alanine, $0.5 \mathrm{~g}$; leucine, $1.3 \mathrm{~g}$; lysine, $1 \mathrm{~g}$; methionine, $0.1 \mathrm{~g}$; ornithine, $0.0714 \mathrm{~g}$; phenylalanine, $0.5 \mathrm{~g}$; proline, $0.5 \mathrm{~g}$; threonine, $0.5 \mathrm{~g}$; biotin (Nutritional Biochemicals Corp.), $1 \mathrm{mg}$; distilled water, 1 litre. The biotin was filter-sterilized and added to the other ingredients after they had been autoclaved at $110^{\circ} \mathrm{C}$ for $20 \mathrm{~min}$. Chemicals, including amino acids, were purchased from Sigma, Calbiochem or Eastman Kodak.

Germination assays. The strains were incubated in YNB at room temperature overnight, harvested in distilled water, washed once by centrifugation and resuspended to a concentration of $1 \times 10^{7} \mathrm{cells}^{-1}$. The media used to foster germination included: (i) single inducers (L-proline and $N$-acetylglucosamine) at a concentration of $0 \cdot 2 \mathrm{mM}$ in 0.033 M-phosphate buffer ( $\mathrm{pH} \mathrm{7.0)}$; (ii) LBC medium; and (iii) lamb serum (Gibco). About $1 \times 10^{6} \mathrm{cells}^{-1}$ were incubated in $1 \mathrm{ml}$ of each medium for $3 \mathrm{~h}$ at $37^{\circ} \mathrm{C}$. The tubes were agitated gently on a Multipurpose Rotator, model 150 (Scientific Industries, Inc.). A loopful of the cells was removed from each of the media, placed on a glass slide and examined microscopically. The percentage of cells with germ tubes was determined by counting 100 cells.

Isolation of the variant strain 300-SG. Cultures of strain 300 were grown overnight at room temperature in YNB. The cells were harvested by centrifugation, washed three times in distilled water and plated on GPA at a level of approximately 100 c.f.u. per plate. Each of the colonies was touched with a sterile toothpick and the adherent cells were transferred to the well of a Micro Test II tissue culture plate (Falcon Plastics: Becton Dickinson) containing LBC medium. The dishes were incubated at $37^{\circ} \mathrm{C}$ for $3 \mathrm{~h}$ and the contents of each well were examined under the low power of a microscope. Further details are given in Results. 
Measurement of growth under standard conditions. Cells of strains 300 and 300-SG were grown in $50 \mathrm{ml}$ YNB or GPB contained in $300 \mathrm{ml}$ side-arm flasks (Bellco Glass). Growth was initiated at a cell concentration of about $5 \times 10^{6}$ cells $\mathrm{ml}^{-1}$ from an overnight culture incubated at $37^{\circ} \mathrm{C}$ (stationary-phase cells). The cultures were grown on a rotary shaker at $37^{\circ} \mathrm{C}$ and growth was assessed by measuring density with a Klett-Summerson photoelectric colorimeter.

Growth suppression by respiratory inhibitors. Two inhibitors, antimycin A (Calbiochem) and salicylhydroxamic acid (SHAM) (Aldrich) were tested for their effect on the growth of strains 300 and 300-SG. The inhibitors, dissolved in $100 \%$ methanol, were added to GPB and cultures were grown as described in the preceding paragraph. Two flasks were used for each experimental condition as follows: medium alone, medium with $1.5 \%$ methanol (final concentration of solvent used to dissolve inhibitors), medium plus $50 \mu \mathrm{M}$-antimycin $\mathrm{A}$, medium plus $5 \mathrm{mM}$-SHAM, and medium plus both antimycin A $(50 \mu \mathrm{M})$ and SHAM ( $5 \mathrm{mM})$. The cultures were grown and monitored as described in the preceding paragraph. Comparisons of the amount of growth in the presence of the inhibitors were made when control cultures (medium and medium with methanol) entered stationary phase.

Colony characteristics in the presence of chlorobenzotriazole. Cells of the two strains were plated on YNB with $1 \%$ $(\mathrm{w} / \mathrm{v})$ glucose and chlorobenzotriazole (Aldrich) ranging in concentration from $10^{-2}$ to $10^{-6} \mathrm{M}$. The colony texture and the microscopic appearance of the cells were recorded.

Colony characteristics in the presence of glucose supplementation. Cells of the two strains were plated on YNB with $1 \%$ and $10 \%$ glucose and on Harrold's medium (Raper \& Fennell, 1965), which contains $40 \%(w / v)$ sucrose. The relative colony size and texture of the two strains and the microscopic appearance of the cells were recorded.

Two-dimensional polyacrylamide gel electrophoresis. This was done as described by O'Farrell (1975). Samples $(50 \mu \mathrm{l})$ containing about $20 \mu \mathrm{g}$ protein were loaded onto the first-dimension (isoelectric focusing) gels containing $3 \%(\mathrm{w} / \mathrm{v})$ acrylamide, $9 \cdot 5 \mathrm{~m}$-urea, $4 \%(\mathrm{v} / \mathrm{v})$ Triton X-100, 2\%(w/v) Ampholines pH 3-10 and 2\%(v/v) Ampholines $\mathrm{pH}$ 5-7. Isoelectric focusing was carried out for 6200 volt-hours. The second dimension was in gels containing $10 \%$ acrylamide, $0.1 \%$ sodium dodecyl sulphate, and $0.375 \mathrm{M}$-Tris ( $\mathrm{pH} 8.8$ ). It was carried out for $3-4 \mathrm{~h}$ at $25 \mathrm{~mA}$ per gel. The gels were stained by the silver nitrate method of Morrissey (1981).

\section{RESULTS AND DISCUSSION}

\section{Isolation of variant, frequency and reversion}

In working with strain 300 of C. albicans, Buckley et al. (1982) recorded that nongerminating variants occurred at a rate of $2 \%$. We tested this strain for the frequency of nongerminating variants. Cells from an overnight culture grown at room temperature in YNB were plated on GPA at about 100 c.f.u. per plate. One thousand individual colonies were each examined in multiwell dishes for their ability to germinate in $\mathrm{LBC}$ medium at $37^{\circ} \mathrm{C}$. All of the clones germinated but in the course of the isolation procedures a small-colony form was observed and subcultured for further study. This isolate, designated 300-SG, was a nongerminating variant and has been used in our study on heat-shock proteins (Dabrowa \& Howard, 1984). We have not determined its frequency beyond the description just given of one instance from amongst $10^{3}$ colonies, but it probably represents a chance observation. It displayed a number of interesting characteristics (e.g. small colony size, nongermination, catenulate arrangement of yeast cells, and stability of morphological characters).

Two hundred individual colonies of strain 300-SG were studied for revertants in multiwell dishes containing LBC medium (see above). Each well contained about $10^{4}$ yeast cells, so approximately $2 \times 10^{6}$ cells were observed. Two cells with germ tubes were detected. Thus, reversion occurred at a rate of 1 per $10^{6}$ cells. The phenotype of the two variants of strain 300 thus far described is quite different (Buckley et al., 1982; Dabrowa \& Howard, 1983, 1984). The reversion rate in strain $300-\mathrm{SG}$ is low and the variant has retained its characteristics for more than three years in our laboratory.

\section{Morphology and germination}

The salient features of the microscopic morphology of strain 300 and the variant strain 300-SG are shown in Fig. 1. Microscopic examination of cell suspensions of strain 300 harvested from cultures grown on YNB for $24 \mathrm{~h}$ at $23^{\circ} \mathrm{C}$ revealed single yeast cells and occasional budding cells. No pseudohyphae or germ tubes were observed in the cell suspensions used as inocula in the studies reported. Yeast cells (blastoconidia) released into LBC medium at 

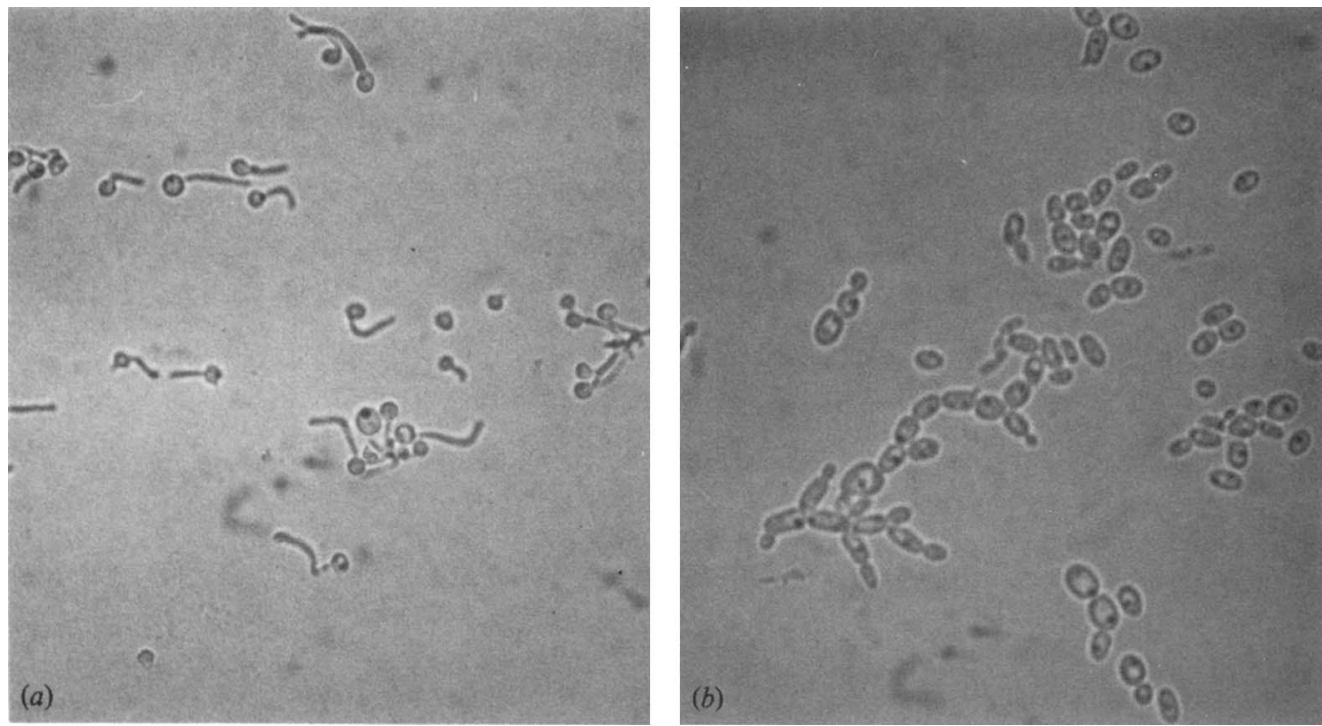

Fig. 1. Microscopic morphology of blastoconidia of strains $300(a)$ and $300-S G(b)$ after $2 \mathrm{~h}$ at $37^{\circ} \mathrm{C}$ in LBC medium. Magnification $\times 450$.
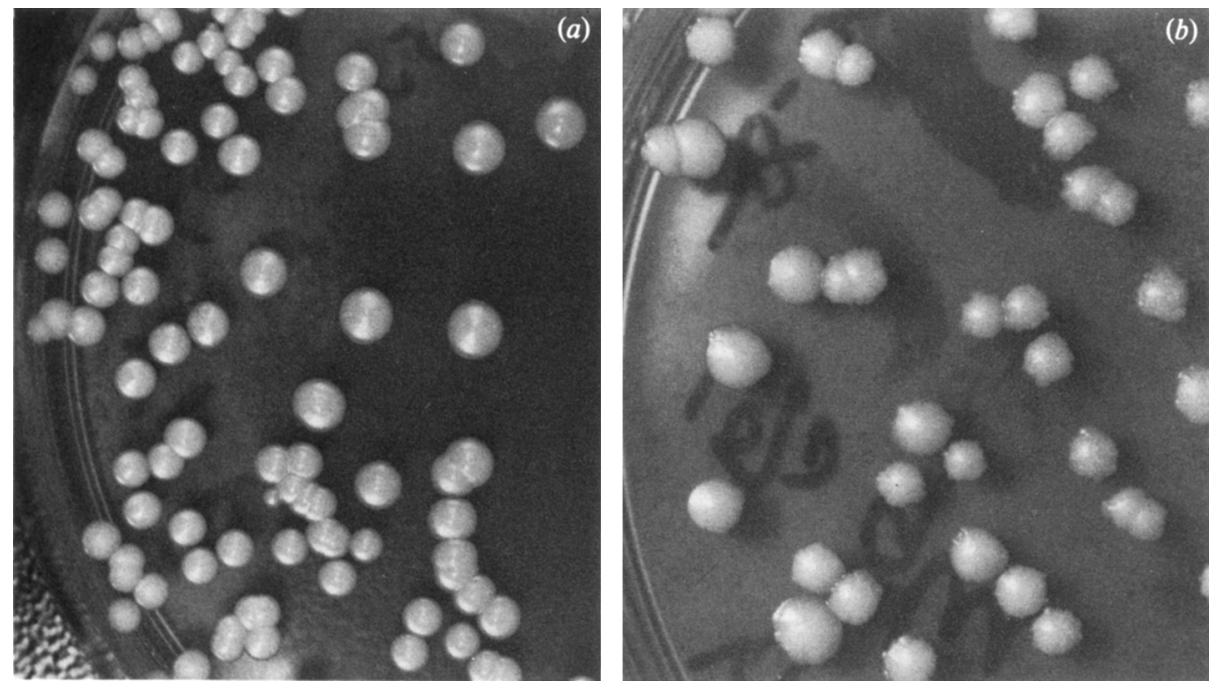

Fig. 2. Colonial morphology of strains $300(a)$ and 300-SG $(b)$ on YNB agar plates incubated for $3 \mathrm{~d}$ at $23^{\circ} \mathrm{C}$.

$37^{\circ} \mathrm{C}$ did not germinate during the first $20 \mathrm{~min}$ of incubation. At 40 min very small germ tubes protruded from about $50-60 \%$ of the cells. At 60 min most of the cells had germ tubes the same length as the diameter of the mother cell, and by $120 \mathrm{~min} 90-95 \%$ of the cells had produced germ tubes at least twice as long as the diameter of the mother cell (Fig. $1 a$ ). During the same period of incubation at $23^{\circ} \mathrm{C}$, the cells remained as single or budded yeast cells. Incubation of the nongerminating variant strain $300-\mathrm{SG}$ at either $23^{\circ} \mathrm{C}$ or $37^{\circ} \mathrm{C}$ in $\mathrm{LBC}$ medium resulted in yeast cell growth with pronounced formation of pseudohyphae (Fig. 1b). No germ tubes were observed regardless of the length of the incubation in $\mathrm{LBC}$ medium at $37^{\circ} \mathrm{C}$. Cells of strain 300 SG did not germinate when incubated at $37^{\circ} \mathrm{C}$ for as long as $24 \mathrm{~h}$ in such common inducers as serum, proline-buffer medium and $N$-acetylglucosamine. 
Table 1. Growth characteristics of strains 300 and 300-SG in YNB at room temperature and at $37^{\circ} \mathrm{C}$

About $5 \times 10^{6}$ cells $\mathrm{ml}^{-1}$ were inoculated into YNB with $1 \%$ glucose initially. Growth was monitored by measurements in a Klett-Summerson photoelectric colorimeter.

$\begin{array}{cccccc} & \overbrace{\text { Room temp. }} & 37^{\circ} \mathrm{C} & & \overbrace{\text { Room temp. }}^{\text {Strain } 300} 37^{\circ} \mathrm{C} \\ \begin{array}{c}\text { Length of lag phase }(\mathrm{h}) \\ \begin{array}{c}\text { Generation time }(\mathrm{h}) \\ \text { in exponential phase }\end{array}\end{array} & 4 & 3 & 7 & 5 \\ \begin{array}{c}\text { Time from inoculation } \\ \text { in stationary phase }\end{array} & 19 & 9 & 1 \cdot 2 & 2 \cdot 6 & 2 \cdot 1 \\ & & & & 24 & 19\end{array}$

\section{Colony morphology}

The appearance of colonies of strain 300 and strain 300-SG is shown in Fig. 2. The colony texture of the nongerminating variant was rough but not nearly as strikingly so as for the UVinduced morphological mutant described by Pomes et al. (1985). The appearance of our smallcolony variant was not distinctive enough to allow detection of sectored colonies among several thousand colonies examined for that attribute.

The small-colony form and the failure to germinate under standard conditions were the two most obvious variations displayed by strain 300-SG. It developed abundant pseudohyphae and chlamydoconidia in corn meal agar and assimilated the carbohydrates characteristic of strains of C. albicans (Silva-Hutner \& Cooper, 1980).

\section{Growth under standard conditions}

Growth of strains 300 and 300-SG in YNB with $1 \%$ glucose was monitored by measuring optical density. The strains each exhibited a lag phase, an exponential phase and a stationary phase. The durations of each of the growth phases varied somewhat from experiment to experiment; representative results from cultures grown at room temperature and at $37^{\circ} \mathrm{C}$ are shown in Table 1. The lag phases of the two strains depended on the temperature of incubation and were consistently longer for the slow-growing variant. The generation times in the exponential phase of growth were prolonged in strain 300-SG and the time required to enter the stationary phase corresponded to the longer lag phase and generation time. Slight differences in the duration of the three phases of growth were observed when GPB was used in place of YNB but the overall behaviour of the two strains was the same. The generation time of strain 300 reported by Buckley et al. (1982) was comparable to that recorded in Table 1 but strain 300-SG was slower growing than B311-V6.

\section{Growth suppression by antimycin $A$ and SHAM}

Small colony forms that are respiratory-deficient mutants have been described in Saccharomyces cerevisiae and Torulopsis glabrata (Fincham et al., 1979). A naturally occurring respiratory-deficient strain of Candida slooffii has been described (Arthur et al., 1978) and petite mutants of several yeast species might be widespread in environments nonselective for respiratory competence (Arthur et al., 1978). A few examples include Torulopsis pintolopesii, Torulopsis lactis-condensi and Schizosaccharomyces japonicus var. versatilis. The petite mutation is reported to be lethal for Candida albicans (Alvarez \& MacKinnon, 1957; Bulder, 1964a, b), but a petite-like variant with an alternative respiratory pathway has been described (Kot et al., 1976).

Yamaguchi $(1974,1975)$ reported that the respiratory activity of yeast cells of $C$. albicans declined when they were placed under germinating conditions. Land et al. (1975) also reported repression of respiration in germinating blastoconidia of $C$. albicans. However, Shepherd et al. (1978) and Aoki \& Ito-Kuwa (1982) presented data that emphasized that repression of respiration did not play an essential role in yeast cell germination, although there is a difference between yeast and mycelial cells in their ability to display the cyanide-insensitive respiratory pathway. 
Table 2. Effect of antimycin $A$ and SHAM on the growth of strains 300 and $300-S G$

Growth was determined at $37^{\circ} \mathrm{C}$ in YNB with $1 \%$ glucose to which was added the indicated solvent and inhibitors. The results represent the amount of growth at the time of entry of control cultures (medium and medium + methanol) into the stationary phase (those times for the experiment recorded were $11 \mathrm{~h}$ for strain 300 and $15 \mathrm{~h}$ for strain 300-SG). Percentage inhibition of growth over that in the medium + methanol control is given in parenthesis.

Growth (Klett units) in:

$\begin{array}{lccccc}\text { Strain } & \text { Medium } & \begin{array}{c}\text { Medium }+ \\ \text { Methanol }(1.5 \%)^{*}\end{array} & \begin{array}{c}\text { Medium }+ \\ \text { Antimycin A }(50 \mu \mathrm{M})\end{array} & \begin{array}{c}\text { Medium + } \\ \text { SHAM (5 mM) }\end{array} & \begin{array}{c}\text { Antimycin A (50 } \mu \text { M }) \\ + \text { SHAM }(5 \text { mM) }\end{array} \\ 300 & 365 & 353 & 87(75 \%) & 228(35 \%) & 59(83 \%) \\ 300-S G & 300 & 295 & 100(66 \%) & 167(43 \%) & 52(82 \%)\end{array}$

* Final concentration of solvent used to dissolve inhibitors.

Respiratory-deficient mutants of Neurospora crassa termed 'poky' have long been known (Brody, 1981). A similar phenotype has been described in a mutant of Arthroderma benhamiae which displayed a defective standard cytochrome system and a functional alternative oxidase pathway (Howard \& Dabrowa, 1979). A branched electron transport system consisting of a standard cytochrome system which is inhibited by cyanide and an alternative oxidase system inhibited by SHAM has been demonstrated in Histoplasma capsulatum (Maresca et al., 1979).

Experiments were undertaken to determine whether the small-colony form and delayed growth rates of strain 300-SG were related to a defect in the standard cytochrome or alternative oxidase systems. Inhibition of growth of strains 300 and 300-SG by antimycin A (cytochrome system) and by SHAM (alternative oxidase system) was studied (Table 2). Antimycin A inhibited the growth of both strains. Therefore there was no evidence for a defect in the cytochrome system of strain 300-SG. Both strains displayed a SHAM-sensitive alternative oxidase system. The two inhibitors together almost completely inhibited growth.

\section{Colony characteristics in the presence of chlorobenzotriazole}

Bianchi (1961) described a small-colony variant of Candida albicans that occurred naturally in cultures at a frequency of about $1-3 \%$. The colony size was due to a slower growth rate and was not related to any defects in the terminal oxidative enzymes. Several of the benzazoles related in structure to benzimidazole, which is an antagonist of adenine metabolism (Woolley, 1944), caused the small-colony variant to grow more rapidly and thereby to produce colonies comparable in size to the wild-type (Bianchi, 1961). The basic defect in the variant which was relieved by the action of benzoles was not precisely identified by Bianchi (1961) but the similarity of colony size and natural occurrence of the variant led us to test the sensitivity of strain 300-SG to benzazoles.

Plates of YNB with $1 \%$ glucose were supplemented with chlorobenzotriazole in the range $10^{-2}-10^{-6} \mathrm{M}$. Strains $300-\mathrm{SG}$ and 300 were plated on supplemented and unsupplemented media and incubated at room temperature and $37^{\circ} \mathrm{C}$. There were no detectable differences in the rate of growth of either strain in any of the concentrations of chlorobenzotriazole tested. The colony size of strain 300-SG was again small in comparison with that of strain 300 regardless of the presence of chlorobenzotriazole. Thus the small-colony variant 300-SG is different from the one described by Bianchi (1961).

\section{Growth characteristics at different levels of utilizable carbohydrates}

A fringe of pseudohyphae occurs at the periphery of colonies of most isolates of C. albicans incubated for long periods on GPA (Rippon, 1982). Such growth results from the decrease in glucose concentration in the vicinity of the colony and is fostered on media devoid of utilizable carbohydrate (Nickerson \& Mankowski, 1953). Ireland \& Sarachek (1968) described a small, rough-colony variant of $C$. albicans. The colonies of the variant became progressively rough during prolonged incubation because of extensive development of pseudohyphae. Supplement- 
ing the medium with large amounts of glucose, intermediates of the tricarboxylic acid cycle or any of several amino acids derived biosynthetically from intermediates of oxidative respiration prevented the formation of pseudohyphae by the variant but did not affect the growth rate or colony size. We decided to test the notation that 300-SG might represent a similar sort of mutant because of its slow growth rate and prominent pseudohyphal appearance in mature colonies. Increasing the glucose concentration in GPA from $1 \%$ to $10 \%$ did not affect the pseudohyphal appearance of strain 300-SG or its growth rate. This same result occurred when 300-SG was cultivated on Harrold's agar, which contains $40 \%$ sucrose. These results suggest that the variant may be a cell-cycle mutant defective at the cell separation stage rather than a variant with an exaggeration of the customary pseudohyphal growth form which is suppressible by excess levels of utilizable carbohydrate.

\section{Protein differences between strains 300 and $300-S G$}

Results of the analysis of the cytoplasmic proteins from strains 300 and 300-SG by sodium dodecyl sulphate-polyacrylamide slab gel electrophoresis have been reported (Dabrowa \& Howard, 1984). This comparison has now been extended by two-dimensional O'Farrell gel analysis. The protein patterns produced on the gels from lysates of cells of each of the strains grown at room temperature revealed very few differences. Approximately 205 proteins were resolved and stained on the gels. Two proteins of apparent $M_{\mathrm{r}} 49000$ and 58000 were present in strain 300 but not in strain 300-SG whilst one protein of apparent $M_{\mathrm{r}} 25000$ was found in strain 300-SG but not in strain 300. However, the efficiency of this method of analysis is open to question since measurements of mRNA complexity in Saccharomyces cerevisiae suggest that 4000 different proteins are synthesized (Hereford \& Rosbash, 1977). Although the total capacity of $C$. albicans to produce different proteins has not been estimated, it is likely to be at least one order of magnitude larger than that detected in our stained gels and thus there is a possibility that some minor strain-specific proteins were not detected. Furthermore, the two-dimensional technique used does not resolve basic proteins. Hence, further work with gradient gels will be needed to resolve possible differences in proteins synthesized by the two strains.

This investigation was supported by Public Health Service grant AI-16252 from the National Institute of Allergy and Infectious Diseases, NIH, Bethesda, MD, and from the University Task Force on AIDS, University of California. We are grateful to Mr Heinrich Kolbel and Ms Eufemia Tsui for skilful technical assistance. We thank Ms Lois Howard for her care in preparing the manuscript and Dr Rishab Gupta for consultation on growth curve analysis. This is publication no. 111 of the Collaborative California Universities-Mycology Research Unit (CCU-MRU).

\section{REFERENCES}

Ahrens, J. C., Daneo-Moore, L. \& Buckley, H. R. (1983). Differential protein synthesis in Candida albicans during blastospore formation at $24.5^{\circ} \mathrm{C}$ and during germ tube formation at $37^{\circ} \mathrm{C}$. Journal of General Microbiology 129, 1133-1139.

Alvarez, A. \& MaCKinnon, J. E. (1957). Lethal variant of Candida albicans, a petite colonie mutant. Science 126, 399-400.

AoKI, S. \& ITo-KuWA, S. (1982). Respiration of Candida albicans in relation to its morphogenesis. Plant and Cell Physiology 23, 721-726.

Arthur, H., Watson, K., McArthur, C. R. \& Clark-Walker, G. D. (1978). Naturally occurring respiratory deficient Candida slooffii strains resemble petite mutants. Nature, London 271, 750-752.

Beneke, E. S. \& Rogers, A. L. (1980). Medical Mycology Manual, 4th edn., p. 126. Minneapolis: Burgess Publishing Company.

BIANCHI, D. E. (1961). Small colony variant in Candida albicans. Journal of Bacteriology 82, 101-105.
BRODY, S. (1981). Genetic and biochemical studies on Neurospora conidia germination and formation. In The Fungal Spore: Morphogenetic Controls, pp. 605626. Edited by G. Turien \& H. R. Hohl. New York: Academic Press.

Brown, L. A. \& Chaffin, W. L. (1981). Differential expression of cytoplasmic proteins during yeast bud and germ tube formation in Candida albicans. Canadian Journal of Microbiology 27, 580-586.

BRummel, M. \& Soll, D. R. (1982). The temporal regulation of protein synthesis during synchronous bud or mycelium formation in the dimorphic yeast Candida albicans. Developmental Biology 89, 211-224.

Buckley, H. R., Price, M. R. \& Daneo-Moore, L. (1982). Isolation of a variant of Candida albicans. Infection and Immunity 37, 1209-1217.

Bulder, C. J. E. A. (1964a). Induction of petite mutation and inhibition of synthesis of respiratory enzyme in various yeasts. Antonie van Leeuwenhoek 30, 1-9. 
BUlder, C. J. E. A. $(1964 b)$. Lethality of the petite mutation in petite negative yeasts. Antonie van Leeuwenhoek 30, 442-454.

Cassone, A., Sullivan, P. A. \& Shepherd, M. G. (1985). $N$-Acetyl-D-glucosamine-induced morphogenesis in Candida albicans. Microbiologica 8, 85-99.

Dabrowa, N. \& Howard, D. H. (1983). Blastoconidium germination. In Fungi Pathogenic For Humans And Animals. Part A : Biology, pp. 525-545. Edited by D. H. Howard. New York: Marcel Dekker.

Dabrowa, N. \& HowaRD, D. H. (1984). Heat shock and heat stroke proteins observed during germination of the blastoconidia of Candida albicans. Infection and Immunity 44, 537-539.

DAHLbERG, K. R. \& VAN EtTEN, J. L. (1982). Physiology and biochemistry of fungal sporulation. Annual Review of Phytopathology 20, 281-301.

Dolan, C. T. \& IHRKE, D. M. (1971). Further studies of germ tube test for Candida albicans identification. American Journal of Clinical Pathology 55, 733-734.

Fincham, J. R. S., DAY, P. R. \& RadFORD, A. (1979). Fungal Genetics, pp. 469-475. Berkeley: University of California Press.

Hasenclever, H. F. (1965). The antigens of Candida albicans. American Review of Respiratory Diseases 92, $150-158$.

Hereford, L. M. \& Rosbash, M. (1977). Number and distribution of polyadenylated RNA sequences in yeast. Cell 20, 453-462.

Howard, D. H. \& Dabrowa, N. (1979). Mutants of Arthroderma benhamiae. Sabouraudia 17, 33-50.

IRELAND, R. \& SARACHEK, A. (1968). A unique minuterough colonial variant of Candida albicans. Mycopathologia et mycologia applicata 35, 346-360.

Kot, E., Olson, V. L., Rolewic, L. J. \& MCClary, D. O. (1976). An alternate respiratory pathway in Candida albicans. Antonie van Leeuwenhoek 42, 33-48.

Land, G. A., Macdonald, W. C., Stjernholm, R. L. \& Friedman, L. (1975). Factors affecting filamentation in Candida Albicans: changes in respiratory activity of Candida albicans during filamentation. Infection and Immunity 12, 119-127.

LeE, K. L., Buckley, H. R. \& CAMpbell, C. C. (1975). An amino acid liquid synthetic medium for the development of mycelial and yeast forms of Candida albicans. Sabouraudia 13, 148-153.

Manning, M. \& Mitchell, T. G. (1980). Morphogenesis of Candida albicans and cytoplasmic proteins associated with differences in morphology, strain, or temperature. Journal of Bacteriology 144, 258-273.

Mardon, D., Balish, E. \& Phillips, A. W. (1969). Control of dimorphism in a biochemical variant of Candida albicans. Journal of Bacteriology 100, 701707.

Maresca, B., Lambowitz, A. M., Kobayashi, G. S. \& MEDOFF, G. (1979). Respiration in the yeast and mycelial phases of Histoplasma capsulatum. Journal of Bacteriology 138, 647-649.

Martin, M. V., Craig, G. T. \& Lamb, D. J. (1984). An investigation of the role of true hypha production in the pathogenesis of oral candidosis. Sabouraudia 22, 471-476.

McGinNis, M. R. (1980). Laboratory Handbook of Medical Mycology, pp. 364-366. New York: Academic Press.
Meyer, S. A., Ahearn, D. G. \& Yarrow, D. (1984). Genus 4. Candida Berkhout. In The Yeasts, 3rd edn, pp. 609-613. Edited by N. J. W. Kreger-van Rij. Amsterdam: Elsevier.

MorRISSEY, J. H. (1981). Silver stain for proteins in polyacrylamide gels: a modified procedure with enhanced uniform sensitivity. Analytical Biochemistry 117, 307-310.

Nickerson, W. J. \& MANkowski, Z. T. (1953). Role of nutrition in the maintenance of the yeast-shape in Candida. American Journal of Botany 40, 584592.

ODDs, F. C. (1979). Candida and candidosis. Baltimore: University Park Press.

O'FARRELL, P. H. (1975). High resolution two-dimensional electrophoresis of proteins. Journal of Biological Chemistry 250, 4007-4021.

Ogletree, F. F., Abdelal, A. T. \& Ahearn, D. G. (1978). Germ tube formation by atypical strains of Candida albicans. Antonie van Leeuwenhoek 44, 1524.

Olaiya, A., Steed, J. \& Sogin, S. (1980). Deoxyribonucleic acid-deficient strains of Candida albicans. Journal of Bacteriology 141, 1284-1290.

Pomes, R., Gil, C. \& Nombela, C. (1985). Genetic analysis of Candida albicans morphological mutants. Journal of General Microbiology 131, 21072113.

RAPER, K. B. \& FEnNell, D. I. (1965). The Genus Aspergillus, p. 40. Baltimore: Williams \& Wilkins.

RIPPON, J. W. (1982). Medical Mycology, p. 520. Philadelphia: W. B. Saunders.

Shepherd, M. G., Chin, C. M. \& Sullivan, P. A. (1978). An alternate respiratory pathway of Candida albicans. Archives of Microbiology 116, 61-67.

Silva-HutNer, M. \& COOPER, B. H. (1980). Yeasts of medical importance. In Manual of Clinical Microbiology, 3rd edn, pp. 562-576. Edited by E. H. Lennette, A. Balows, W. J. Hausler, Jr \& J. P. Truant. Washington, DC: American Society for Microbiology.

Sobel, J. D., Muller, G. \& BuCkley, H. R. (1984). Critical role of germ tube formation in the pathogenesis of candidal vaginitis. Infection and Immunity 44, 576-580.

Szaniszlo, P. J., JaCOBS, C. W. \& GeIs, P. A. (1983). Dimorphism: morphological and biochemical aspects. In Fungi Pathogenic For Humans And Animals. Part A: Biology, pp. 323-436. Edited by D. H. Howard. New York: Marcel Dekker.

TorosantuCCI, A. \& Cassone, A. (1983). Induction and morphogenesis of chlamydospores in an agerminative variant of Candida albicans. Sabouraudia 21, 49-57.

WOOLLEY, D. W. (1944). Growth inhibition in yeast and bacteria by benzimidazole. Journal of Biological Chemistry 152, 225-232.

YamaGuCHI, H. (1974). Dimorphism in Candida albicans. I. Morphology-dependent changes in cellular content of macromolecules and respiratory activity. Journal of General and Applied Microbiology 20, 87-99.

YaMAGUCHI, H. (1975). Control of dimorphism in Candida albicans by zinc: effect on cell morphology and composition. Journal of General Microbiology 86, 370-372. 